\title{
A Phase I Study of S-1-based Concurrent Chemoradiotherapy Followed by Gemcitabine and S-1 in Metastatic Pancreatic Adenocarcinoma
}

\author{
SHIH-HUNG YANG ${ }^{1,2,3}$, YU-YUN SHAO ${ }^{1,4}$, CHIA-CHI LIN ${ }^{1,4}$, SUNG-HSIN KUO ${ }^{1,4,5}$, \\ ANN-LII CHENG ${ }^{1,2,4,5}$ and KUN-HUEI YEH ${ }^{1,3,4,5}$

\begin{abstract}
Departments of ${ }^{1}$ Oncology and ${ }^{2}$ Internal Medicine, National Taiwan University Hospital, Taipei, Taiwan, R.O.C.; Graduate Institutes of ${ }^{3}$ Clinical Medicine, ${ }^{4}$ Oncology, and ${ }^{5}$ National Taiwan University Cancer Center,
\end{abstract} \\ National Taiwan University College of Medicine, Taipei, Taiwan, R.O.C.
}

\begin{abstract}
Background/Aim: Radiotherapy is not routinely used in metastatic pancreatic ductal adenocarcinoma (PDAC). We conducted a phase I study to investigate concurrent chemoradiotherapy (CCRT) followed by chemotherapy. Materials and Methods: S-1 was administered at $50-70 \mathrm{mg} / \mathrm{m}^{2} /$ day with radiotherapy in 2.5-3.6 Gy/day for 10-12 fractions. After CCRT, gemcitabine $\left(1,000 \mathrm{mg} / \mathrm{m}^{2}\right.$ on days 1 and 15) and $S-1$ (60-100 mg/day on days 1-7 and 15-21), were administered in a 4-week cycle. Results: After enrolling 10 patients, the study was terminated due to slow recruitment. Dose-limiting toxicities and maximum tolerated doses were not identified. Most patients experienced mild toxicities, including nausea, vomiting, and anorexia. One patient developed grade 3 infection. One patient achieved partial remission, while the remaining nine patients had stable disease, with a local disease control rate of $100 \%$ after CCRT. Conclusion: A short-course CCRT followed by chemotherapy was potentially feasible in patients with metastatic PDAC.
\end{abstract}

Pancreatic ductal adenocarcinoma (PDAC) is an aggressive cancer type with a high potential for early metastasis and a poor prognosis. More than 50\% of patients with PDAC are diagnosed with locally advanced or metastatic disease. Palliative

Correspondence to: Kun-Huei Yeh, MD, Ph.D., Professor, Department of Oncology, National Taiwan University Hospital, No. 7, Chung-Shan South Road, Taipei 10002, Taiwan, R.O.C. Tel: +886 223123456, ext. 67514, Fax: +886 223711174, e-mail: khyeh@ntu.edu.tw; and Sung-Hsin Kuo, MD, Ph.D., Division of Radiation Oncology Department of Oncology, National Taiwan University Hospital, No. 7, Chung-Shan South Road, Taipei 10002, Taiwan, R.O.C. Tel: +886 223123456, ext. 67144, Fax: +886 223711174,e-mail: shkuo101@ntu.edu.tw

Key Words: Pancreatic ductal adenocarcinoma, metastasis, radiotherapy, S-1, gemcitabine. chemotherapy typically has been administered as the standard treatment. First, in a landmark study of advanced PDAC, an overall response rate (RR) of $5.4 \%$ and overall survival (OS) of 5.65 months were demonstrated in patients receiving gemcitabine monotherapy (1). The MPACT (Metastatic Pancreatic Adenocarcinoma Clinical Trial) study, on patients with metastatic PDAC, demonstrated the superiority of gemcitabine and nab-paclitaxel combination over gemcitabine alone, in terms of RR (23\% vs. 7\%), progression-free survival (PFS) (5.5 vs. 3.7 months), and OS (8.5 vs. 6.7 months), respectively (2). Besides, the GEST (Gemcitabine and S-1 Trial) study on patients with locally-advanced or metastatic PDAC, demonstrated a better RR (29.3\% vs. $13.3 \%)$ and PFS (5.7 months vs. 4.1 months) in patients who received a combination of gemcitabine and S-1 (GS) than with gemcitabine alone (3).

An important limitation of utilizing these combinational regimens of phase III studies in the routine treatment of locally advanced or metastatic PDAC is toxicity (2-4). The FOLFIRINOX regimen, comprising oxaliplatin, irinotecan, and fluorouracil (5-FU), showed promise, with a RR of $31.6 \%$, median PFS of 6.4 months, and median OS of 11.1 months in patients with metastatic PDAC. However, $45.7 \%$ of these patients experienced grade 3 or higher neutropenia, with $42.5 \%$ receiving granulocyte colony-stimulating factor (G-CSF) for hematopoietic support; other grade 3 or higher non-hematological toxicities, such as fatigue, vomiting, and diarrhea, were also significant in these patients (4). The development of grade 3 or higher neutropenia was also common in regimens using gemcitabine plus either nabpaclitaxel or S-1 $(2,3)$. Even though the feasibility of combinational chemotherapeutic regimens in the treatment of locally advanced or metastatic PDAC was demonstrated in clinical trials (2-5), the OS was actually much worse for patients with variable performance status (PS) who received chemotherapy in usual daily practice $(6,7)$. Our previous study also demonstrated that patients with locally advanced 
Table I. Schedule of radiotherapy and $S-1$.

\begin{tabular}{lccccc}
\hline Dose level & 1 & 2 & 3 & 4 & 5 \\
\hline $\mathrm{S}-1$ & $50 \mathrm{mg} / \mathrm{m}^{2} /$ day & $50 \mathrm{mg} / \mathrm{m}^{2} /$ day & $60 \mathrm{mg} / \mathrm{m}^{2} /$ day & $60 \mathrm{mg} / \mathrm{m}^{2} / \mathrm{day}$ & $70 \mathrm{mg} / \mathrm{m}^{2} / \mathrm{day}$ \\
& Day $1-14$ & Day $1-14$ & Day $1-14$ & Day $1-16$ & Day $1-16$ \\
RT & $25 \mathrm{~Gy} / 10 \mathrm{fx}$ & $30 \mathrm{~Gy} / 10 \mathrm{fx}$ & $30 \mathrm{~Gy} / 10 \mathrm{fx}$ & $36 \mathrm{~Gy} / 12 \mathrm{fx}$ & $36 \mathrm{~Gy} / 12 \mathrm{fx}$ \\
& $2.5 \mathrm{~Gy} / \mathrm{fx}$ & $3 \mathrm{~Gy} / \mathrm{fx}$ & $3 \mathrm{~Gy} / \mathrm{fx}$ & $3 \mathrm{~Gy} / \mathrm{fx}$ & $3 \mathrm{~Gy} / \mathrm{fx}$ \\
& D1-5, D8-12 & D1-5, D8-12 & D $1-5, \mathrm{D} 8-12$ & $\mathrm{D} 1-5,8-12,15-16$ & $\mathrm{D} 1-5,8-12,15-16$ \\
\hline
\end{tabular}

afx: Fraction.

or metastatic PDAC who did not participate in clinical trials had worse prognosis (median OS, 5.4 months, gemcitabinebased regimens) than patients who did (6).

The physical conditions of patients with PDAC are fragile and often precluded from typical cancer treatments due to local tumor-associated symptoms, such as pain, jaundice with biliary tract infection, and vomiting with duodenal obstruction (8). Radiotherapy (RT) is a part of the standard therapeutic approach for locally advanced disease of PDAC (9) and has shown benefits in local control of this disease $(10,11)$. However, the local disease control rate (DCR) for locally advanced and metastatic PDAC is no more than $70 \%$ with chemotherapy alone $(4,10)$. Since RT is not a standard therapy for metastatic PDAC, it is rarely used for this subgroup of patients $(12,13)$. Although the benefit of RT for OS in metastatic PDAC was noted $(12,13)$, it is frequently overlooked and has not been investigated in prospective studies.

The chemotherapy drug, $\mathrm{S}-1$, is an oral fluoropyrimidine with radiosensitizing effects, and comprising tegafur, gimeracil, and oteracil potassium (14). The single-agent activity of S-1 and a high DCR of S-1-based CCRT were demonstrated in studies of advanced PDAC $(3,11)$. The goal of this study was to test the feasibility of RT in metastatic PDAC. To accomplish this, a phase I study was designed to evaluate the safety of a short course of S-1-based CCRT followed by systemic chemotherapy with a combination of gemcitabine and S-1. In addition, the benefits of local control of RT in metastatic PDAC were also explored, especially in those with low-risk PANcreatic Cancer Extent Score (PANCES).

\section{Materials and Methods}

Eligibility criteria. This was a single-institution, phase I trial. Eligible subjects were assigned in a $3+3$ trial design. To be eligible, patients had to meet all of the following criteria: 1) newly diagnosed, histologically or cytologically proven metastatic PDAC; 2) no prior RT, surgery, or systemic therapy for PDAC; 3) at least one measurable lesion; 4) age between 20 and 79 years; 5) ECOG (Eastern Cooperative Oncology Group) PS of 0 or $1 ; 6$ ) adequate organ function defined as: white blood cell (WBC) count $\geq$ $3,500 / \mu \mathrm{l}$, hemoglobin $(\mathrm{Hgb}) \geq 9.0 \mathrm{~g} / \mathrm{dl}$, platelet $\geq 100 \times 10^{3} / \mu \mathrm{l}$, total bilirubin $\leq 2.0 \mathrm{mg} / \mathrm{dl}$, liver transaminases $\leq 2.5$ times the upper limit of normal value (ULN), creatinine $\leq 1.2 \mathrm{mg} / \mathrm{dl}$, and creatinine clearance $\geq 50 \mathrm{ml} / \mathrm{min}$. For subjects with biliary drainage, total bilirubin $\leq 3.0 \mathrm{mg} / \mathrm{dl}$ was acceptable. Key exclusion criteria were as follows: 1) lung fibrosis or interstitial pneumonitis noted within 28 days prior to screening; 2) diarrhea $\geq$ Common Terminology Criteria for Adverse Events (CTCAE) v.4.03 grade 2; 3) active infection; 4) significant co-morbidities; 5) moderate or severe ascites or pleural effusion that requires drainage; 6) central nervous system metastasis; 7) prior or concurrent malignancies within the last 3 years; 8) concomitant use of flucytosine, phenytoin or warfarin; and 9) positive pregnancy test for women of childbearing potential, pregnant women, or nursing mothers.

Informed consent was obtained from all individual participants included in the study. The study was approved by the Research Ethical Committee (REC) of the National Taiwan University Hospital (REC number: 201211048MPC). All procedures performed in studies involving human participants were in accordance with the ethical standards of the institutional and/or national research committee and with the 1964 Helsinki declaration and its later amendments or comparable ethical standards.

Radiotherapy. Based on the pre-defined dose levels, RT was administered, in 2.5 to 3.6 Gy fractions per day for 10-12 fractions totally, to the gross tumor and regional lymphatics in the CCRT (Table I). For RT, $10 \mathrm{MV}$ photons were used, with a volumetric modulated arc technique (VMAT). The gross tumor volume (GTV) was defined as the primary tumor and any involved nodes according to computed tomography (CT) or magnetic resonance imaging (MRI) examination. The standard-risk clinical target volume (CTV) included the GTV plus the regional lymph nodes (i.e., peripancreatic, celiac, superior mesenteric, porta hepatic, retroperitoneal). The CTV was expanded to an internal target volume using four-dimensional CT (4D-CT) to account for respiratory motion. The planning target volume (PTV) was a 3-5 $\mathrm{mm}$ expansion of the internal target volume for patients who underwent 4D-CT. For patients without 4D-CTs, the inferior and superior margins of the CTV were increased to $8-10 \mathrm{~mm}$ to define the PTV. The RT planning, dose distribution, and the dose-volumehistogram of a representative case are demonstrated in Figure 1.

Chemotherapy. In the CCRT portion of treatment, patients received concurrent RT and S-1. The schedule of RT and S-1 is shown in Table I. The dose of S-1 was calculated based on body surface area (BSA), but the actual daily dose of S-1 was based on the lower boundary of the range of BSA. The boundaries of BSA were defined as: $<1.25 \mathrm{~m}^{2}$, $1.25 \mathrm{~m}^{2}$ to $<1.5 \mathrm{~m}^{2}, 1.5 \mathrm{~m}^{2}$ to $<1.75 \mathrm{~m}^{2}, 1.75 \mathrm{~m}^{2}$ to $<2 \mathrm{~m}^{2}$, and $\geq 2 \mathrm{~m}^{2}$. If any dose was interrupted during CCRT, S-1 was continued to complete the total doses required at a given dose level. 

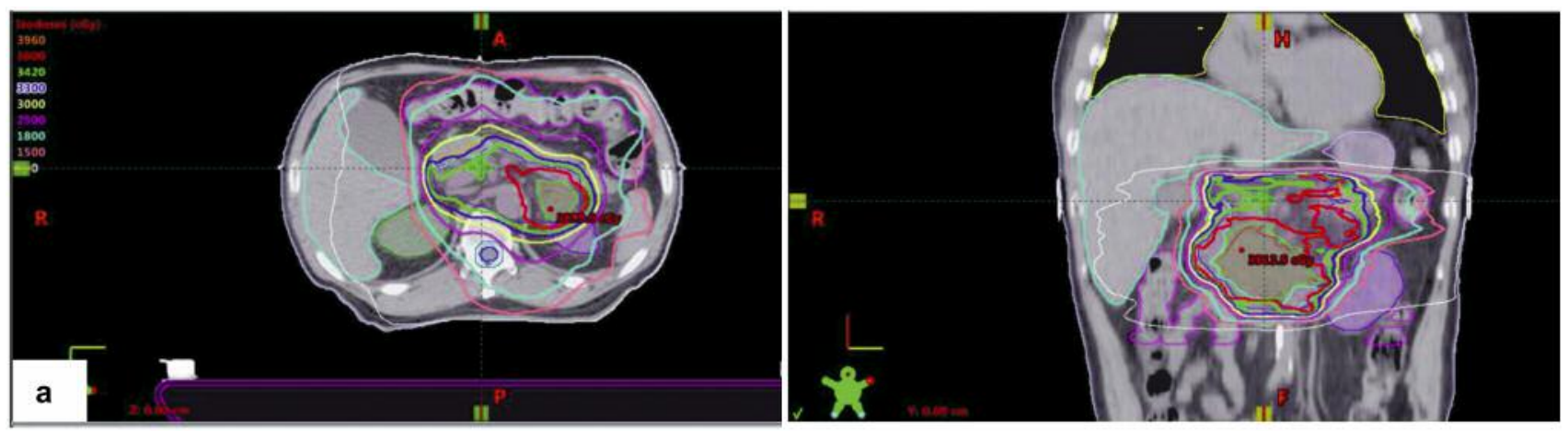

Cumulative Dose Volume Histogram

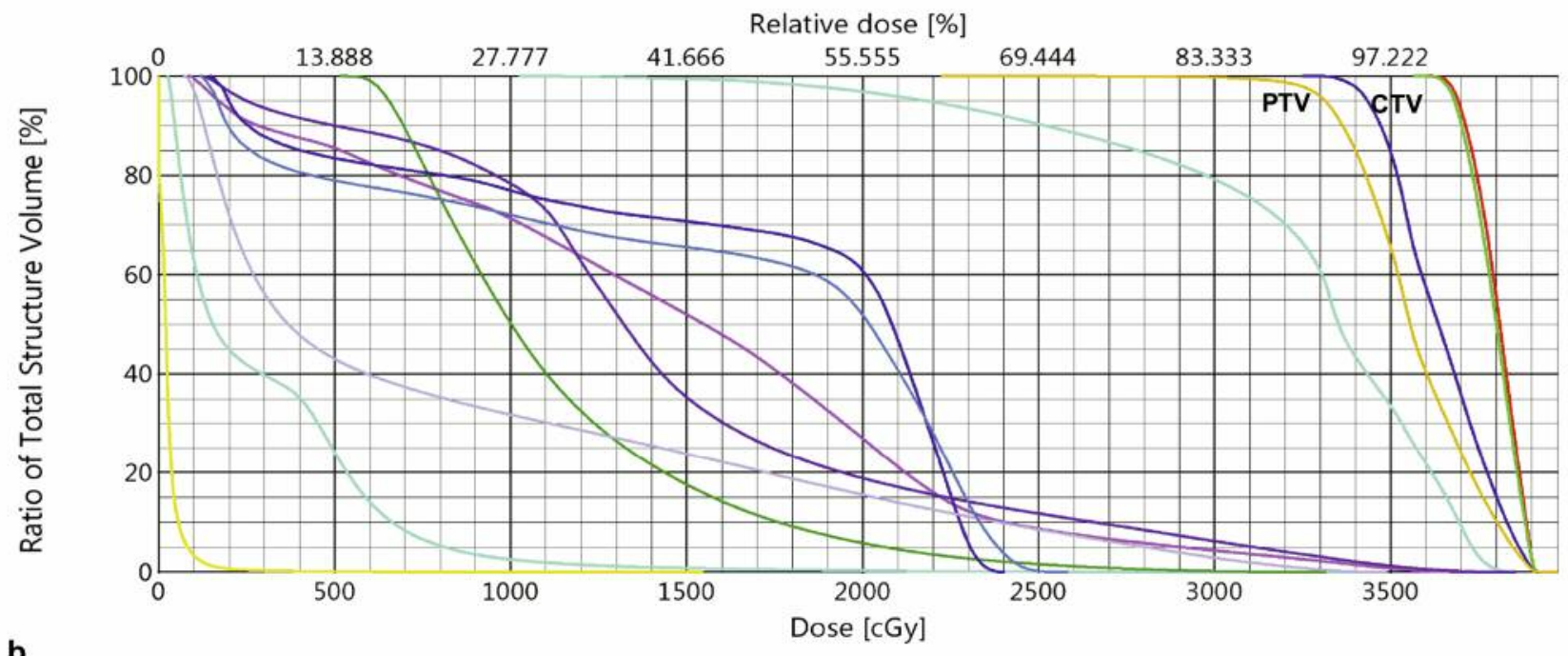

b

\begin{tabular}{|c|c|c|}
\hline & Structure & Structure Statu \\
\hline & Spinal cord & Approved \\
\hline & Duodenum & Approved \\
\hline & SC_PRV & Approved \\
\hline & 01ITV $36 \mathrm{~Gy} 12 \mathrm{fx}$ & Approved \\
\hline & $\begin{array}{l}\text { Stomaach } \\
\text { Right Kidney }\end{array}$ & $\begin{array}{l}\text { Approved } \\
\text { Approved }\end{array}$ \\
\hline & Left Kidney & Approved \\
\hline
\end{tabular}

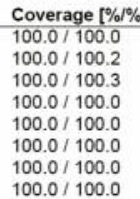

Volume
$18.7 \mathrm{~cm}^{3}$
$57.0 \mathrm{~cm}^{3}$
$72.0 \mathrm{~cm}^{3}$
$113.2 \mathrm{~cm}^{3}$
$138.6 \mathrm{~cm}^{3}$
$216.2 \mathrm{~cm}^{3}$
$222.4 \mathrm{~cm}^{3}$
$268.5 \mathrm{~cm}^{2}$

\begin{tabular}{ll} 
Min Dose & Max Dose \\
\hline 146.3 cGy & 2406.2 cGy \\
1024.1 cGy & 3855.9 cGy \\
116.7 cGy & 2584.7 cGy \\
3581.3 cGy & 3936.9 cGy \\
3565.2 cGy & 3936.9 cGy \\
69.6 cGy & 3489.6 cGy \\
514.2 cGy & 3319.8 cGy \\
121.7 cGy & 3856.5 cGy
\end{tabular}

Mean Dose
$1676.6 \mathrm{cGy}$
$3241.8 \mathrm{cGy}$
$1584.2 \mathrm{cGy}$
$3804.1 \mathrm{cGy}$
$3795.3 \mathrm{cGy}$
$857.7 \mathrm{cGy}$
$1130.0 \mathrm{cGy}$
$1459.1 \mathrm{cGy}$

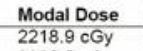

3325.5 cGy $\quad 3351.7$ cGy $\quad 474.9$ cGy

170.0 cGy 2019.1 CGy $\quad 818.8$ cGy

3829.9 cGy 3809.9 cGy $\quad 63.3$ cGy

$\begin{array}{lll}132.6 \mathrm{cGy} & 3800.1 \mathrm{cGy} & 66.2 \mathrm{cGy} \\ 768.1 \mathrm{cGy} & 900.7 \mathrm{cGy}\end{array}$

$\begin{array}{lll}738.6 \mathrm{cGy} & 1001.9 \mathrm{cGy} & 447.7 \mathrm{cGy}\end{array}$

$\begin{array}{lll}1168.3 \mathrm{cGy} & 1321.6 \mathrm{cGy} \quad & 764.1 \mathrm{cGy}\end{array}$

Figure 1. Isodose curves and a dose-volume histogram of the volume metric radiotherapy technique using two full arcs (181-179 degrees; 179-181 degrees) of an example case. (a). Left panel, isodose curve displayed in the axial plane; Right panel, isodose curve displayed in the coronal plane; (b). A dose-volume histogram; SC spinal cord, GTV gross target volume, ITV internal target volume, CTV clinical target volume, PTV planning target volume.

After 3 to 6 weeks of rest following CCRT, patients entered the GS part of treatment with $1000 \mathrm{mg} / \mathrm{m}^{2}$ of gemcitabine administered via intravenous infusion over $30 \mathrm{~min}$, on days 1 and 15 , respectively, concurrently with $60-100 \mathrm{mg} /$ day of S-1 on day $1-7$, and days 15-21, over a 4-week cycle. The actual daily dose of S-1 for each subject in the GS treatment portion was based on the BSA. The daily dose of S-1 at $60 \mathrm{mg}, 80 \mathrm{mg}$, or $100 \mathrm{mg}$ was given if the BSA was $<1.25 \mathrm{~m}^{2}, 1.25 \mathrm{~m}^{2}$ to $<1.5 \mathrm{~m}^{2}$, and $\geq 1.5 \mathrm{~m}^{2}$. Dose reduction of S-1 and gemcitabine in the GS treatment portion was allowed and based on the severities of specific drug-associated toxicities. The treatment was continued until delayed dosing was more than the predefined time limit, disease progression, or death.

Dose-limiting toxicity (DLT). The dose-limiting toxicity (DLT) was based on CTCAE (Common Terminology Criteria for Adverse Events) v.4.03, and defined as the following manifestations of toxicity observed until the completion of CCRT: 1) grade 3 leucopenia and/or neutropenia with a fever $\geq 38^{\circ} \mathrm{C}$ lasting for $\geq 3$ days or with infection; 2) grade 4 leucopenia and/or neutropenia lasting for $\geq 3$ days or requiring G-CSF; 3 ) grade 3 thrombocytopenia requiring transfusion; 
Table II. PANcreatic Cancer Extent Score (PANCES) (N=9).

\begin{tabular}{|c|c|c|c|c|c|c|c|c|c|c|c|c|c|c|c|}
\hline Metastatic lesions & $0-5$ & $6-10$ & $11-15$ & $16-20$ & $21-25$ & $26-30$ & $31-35$ & $36-40$ & $41-45$ & $46-50$ & $51-55$ & $56-60$ & $61-65$ & $66-70$ & $71-75$ \\
\hline Score & 1 & 2 & 3 & 4 & 5 & 6 & 7 & 8 & 9 & 10 & 11 & 12 & 13 & 14 & 15 \\
\hline $\begin{array}{l}\text { Case } \\
\text { No. }\end{array}$ & \multicolumn{3}{|c|}{$\begin{array}{c}\text { Pancreatic } \\
\text { tumor size }(\mathrm{cm})\end{array}$} & \multicolumn{3}{|c|}{$\begin{array}{l}\text { Liver metastasis } \\
\text { score (LiMS) }\end{array}$} & \multicolumn{3}{|c|}{$\begin{array}{l}\text { Lung metastasis } \\
\text { score (LuMS) }\end{array}$} & \multicolumn{4}{|c|}{$\begin{array}{l}\text { Peritoneum metastasis } \\
\text { score (PeMS) }\end{array}$} & \multicolumn{2}{|c|}{ PANCESa } \\
\hline 1 & \multicolumn{3}{|c|}{10.91} & \multicolumn{3}{|c|}{1} & \multicolumn{3}{|c|}{15} & \multicolumn{4}{|c|}{0} & \multicolumn{2}{|c|}{218.2} \\
\hline 2 & \multicolumn{3}{|c|}{3.31} & \multicolumn{3}{|c|}{0} & \multicolumn{3}{|c|}{1} & \multicolumn{4}{|c|}{0} & \multicolumn{2}{|c|}{3.31} \\
\hline 3 & \multicolumn{3}{|c|}{6.36} & \multicolumn{3}{|c|}{6} & \multicolumn{3}{|c|}{0} & \multicolumn{4}{|c|}{0} & \multicolumn{2}{|c|}{190.8} \\
\hline 5 & \multicolumn{3}{|c|}{3.81} & \multicolumn{3}{|c|}{0} & \multicolumn{3}{|c|}{0} & \multicolumn{4}{|c|}{2} & \multicolumn{2}{|c|}{7.62} \\
\hline 6 & \multicolumn{3}{|c|}{6.54} & \multicolumn{3}{|c|}{7} & \multicolumn{3}{|c|}{0} & \multicolumn{4}{|c|}{0} & \multicolumn{2}{|c|}{228.9} \\
\hline 7 & \multicolumn{3}{|c|}{2.99} & \multicolumn{3}{|c|}{3} & \multicolumn{3}{|c|}{0} & \multicolumn{4}{|c|}{0} & \multicolumn{2}{|c|}{44.85} \\
\hline 8 & & 3.9 & & & 1 & & & 0 & & & & 0 & & & 19.5 \\
\hline 9 & & 4.65 & & & 11 & & & 0 & & & & 0 & & & 255.75 \\
\hline 10 & & 4.67 & & & 1 & & & 0 & & & & 0 & & & 23.35 \\
\hline
\end{tabular}

aPANCES $=($ LiMS $\times 5+$ LuMS + PeMS $) \times$ Pancreatic tumor size

Table III. Clinical characteristics and outcomes.

\begin{tabular}{|c|c|c|c|c|c|c|c|c|c|c|c|c|c|}
\hline Case & Age & Gender & PS & Primary & Staging & $\begin{array}{l}\text { Metastatic } \\
\text { sites }\end{array}$ & $\begin{array}{l}\text { Dose } \\
\text { level }\end{array}$ & $\begin{array}{c}\text { Actual S-1 } \\
\text { dose in CCRT } \\
\text { (mg/day) }\end{array}$ & $\begin{array}{c}\text { Average DI } \\
\text { of } \mathrm{S}-1 \\
\text { in CCRT }\end{array}$ & $\begin{array}{c}\text { CCRT } \\
\text { response } \\
\text { (local/distant) }\end{array}$ & $\begin{array}{c}\text { GS } \\
\text { (cycle) }\end{array}$ & $\begin{array}{c}\text { GS } \\
\text { response } \\
\text { (overall) }\end{array}$ & $\begin{array}{c}\text { OS } \\
\text { (month) }\end{array}$ \\
\hline 1 & 53 & $\mathrm{~F}$ & 1 & body, tail & T4N1 & liver, lung & 1 & 40 & $92 \%$ & $\mathrm{SD} / \mathrm{PD}$ & 3 & PD & 5.6 \\
\hline 2 & 64 & $\mathrm{~F}$ & 0 & head & T4N1 & lung & & 51 & & $\mathrm{SD} / \mathrm{SD}$ & 5 & PR & 24.5 \\
\hline 3 & 59 & M & 1 & body, tail & T4N1 & liver & & 47 & & $\mathrm{SD} / \mathrm{PD}$ & 3 & PD & 9.0 \\
\hline 4 & 65 & M & 1 & head & T4N1 & liver & 2 & 42 & $89 \%$ & $\mathrm{SD} / \mathrm{PD}$ & 0 & - & 1.9 \\
\hline 5 & 63 & M & 1 & head & T4N1 & peritoneal & & 45 & & $\mathrm{SD} / \mathrm{SD}$ & 11 & SD & 15.1 \\
\hline 6 & 66 & M & 0 & tail & T4N1 & liver, bone & & 47 & & $\mathrm{SD} / \mathrm{PD}$ & 3 & PD & 4.1 \\
\hline 7 & 70 & $\mathrm{~F}$ & 1 & head & T3N0 & liver & 3 & 54 & $99 \%$ & $\mathrm{SD} / \mathrm{SD}$ & 6 & SD & 9.8 \\
\hline 8 & 74 & M & 1 & body, tail & T4N1 & liver & & 60 & & $\mathrm{SD} / \mathrm{PD}$ & 8 & SD & 13.7 \\
\hline 9 & 42 & $\mathrm{M}$ & 1 & head & T4N1 & liver & & 64 & & $\mathrm{SD} / \mathrm{PD}$ & 1 & $\mathrm{SD}$ & 2.0 \\
\hline 10 & 54 & M & 1 & head & T4N1 & liver & 4 & 52 & $87 \%$ & $\mathrm{PR} / \mathrm{SD}$ & 4 & PD & $15.8+$ \\
\hline
\end{tabular}

Staging: The American Joint Committee on Cancer, 7th edition. CCRT: Concurrent chemoradiotherapy; DI: dose intensity (definition: sum of actual doses divided by sum of predefined doses in each dose level); GS: gemcitabine plus S-1; OS: overall survival; PD: progressive disease, PR: partial remission; SD: stable disease; PS: ECOG performance status.

4) hemoglobin $(\mathrm{HB})<8.0 \mathrm{~g} / \mathrm{dl} ; 5)$ liver transaminases $\geq 10$ times of upper limit of normal value (ULN); 6) total bilirubin $\geq 3$ times of ULN; 7) creatinine $>3$ times of ULN; 8) grade 3 other non-hematological toxicities except infection; and 9) grade 4 infection.

Statistical analysis. The primary endpoint was to obtain the safety profiles and estimate the maximal tolerated dose (MTD) of concomitant S-1 and RT. Secondary endpoints were PFS, OS, RR of CCRT, RR of GS, and CA 19-9 response. The response of CA199 for treatment of PDAC was defined as a $\geq 50 \%$ decrease when compared to the baseline values. Statistical analyses were performed using IBM SPSS for Windows, Version 20.0 (Armonk, NY, USA: IBM Corp). The significance level was $p<0.05$.

The quality of life (QOL) was assessed with concomitant use of the EORTC (European Organisation for Research and Treatment of Cancer) QLQ-C30 (version 3) (15) and QLQ-PAN26 (16) questionnaires completed on day $1,8,15$, of CCRT, and day 1 of each cycle of GS. As for the calculation of QOL, we simply added the individual scores together within the same categories. The preCCRT scores were defined as 100, and the dynamic changes from the pre-CCRT scores were calculated.

We developed the PANCES and analyzed the association between OS and PANCES. The PANCES was calculated according to the metastatic lesions of liver, lung, and peritoneum, as well as the pancreatic tumor size. As shown in Table II, the PANCES $=$ (score of metastatic liver lesions $\times 5+$ score of metastatic lung lesions + score of metastatic peritoneal lesions) $\times$ pancreatic tumor size $(\mathrm{cm})$. Considering the poor prognostic role of liver metastasis, we simply used an integer (from 1 to 10) coefficient to weight the liver metastasis score in the model. We analyzed the association between OS and the individual PANCES with the weighting coefficient. According to the strength of association in terms of the level of R2 between OS and individual PANCES, the model with the weighting coefficient of 5 (or 6) for the liver metastasis score had the highest $\mathrm{R}^{2}$.

This trial was registered at ClinicalTrials.gov (Identifier: NCT01946646). 


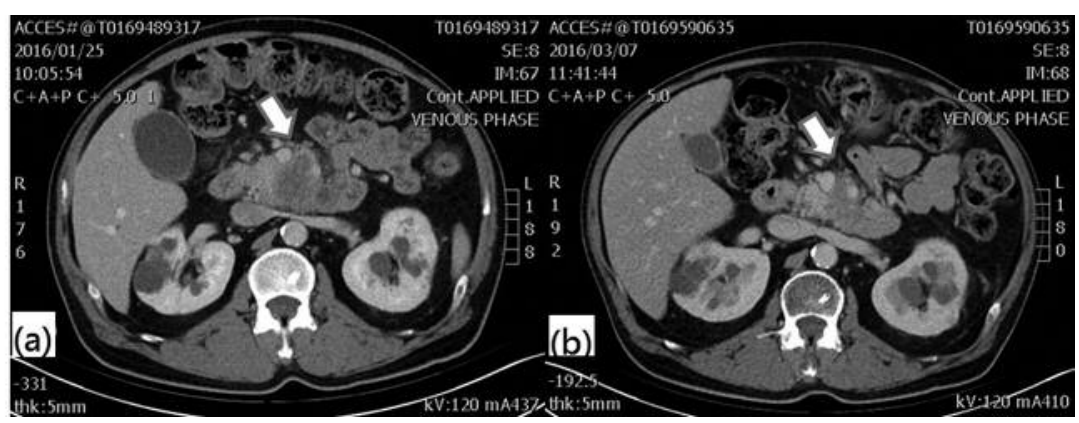

Figure 2. Abdominal computed tomography scans before and after concurrent chemoradiotherapy (CCRT) displayed in the axial plane. (a). Before $C C R T$, arrow indicates the pancreatic body tumor. (b). After CCRT, arrows indicate partial remission of the pancreatic body tumor.

Table IV. Treatment-related adverse events in the CCRT part.

\begin{tabular}{|c|c|c|c|c|c|c|c|c|c|c|}
\hline \multirow[t]{2}{*}{ Adverse events } & \multicolumn{2}{|c|}{ Total } & \multicolumn{2}{|c|}{ Level 1} & \multicolumn{2}{|c|}{ Level 2} & \multicolumn{2}{|c|}{ Level 3} & \multicolumn{2}{|c|}{ Level 4} \\
\hline & Any grade & $\geq$ Gr 3 & Any grade & $\geq$ Gr 3 & Any grade & $\geq$ Gr 3 & Any grade & $\geq$ Gr 3 & Any grade & $\geq$ Gr 3 \\
\hline \multicolumn{11}{|l|}{ Leucopenia } \\
\hline \multicolumn{11}{|l|}{ Neutropenia } \\
\hline Anemia & 2 & & 1 & & 1 & & & & & \\
\hline Nausea & 6 & & & & 3 & & 3 & & & \\
\hline Vomiting & 6 & & 2 & & 2 & & 2 & & & \\
\hline Anorexia & 3 & & 1 & & 2 & & & & & \\
\hline Diarrhea & 1 & & 1 & & & & & & & \\
\hline Fatigue & 1 & & 1 & & & & & & & \\
\hline Liver & 2 & & 1 & & 1 & & & & & \\
\hline Infection & 1 & 1 & 1 & 1 & & & & & & \\
\hline
\end{tabular}

\section{Results}

From October 2013 to January 2016, a total of 10 patients were enrolled at our hospital. The clinical characteristics and outcomes of the patients are shown in Table III. Due to slow recruitment, the study was prematurely terminated after treating the first patient at dose level 4.

All patients had completed the CCRT part of the treatment. Two patients had a short-term interruption of CCRT due to urinary tract infection in one patient and obstructive jaundice with biliary tract infection (BTI) in the other. However, CCRT was restarted within 7 days. Due to poorly controlled diabetes mellitus induced nonketotic hyperosmolar syndrome, one patient did not proceed to the GS portion of treatment. The median drug-free interval after CCRT and before initiation of the GS part of treatment was 23 days (range=20-29 days). The median cycle number of GS administered was 4 (range $=1-11$ cycles). No dose reduction of gemcitabine and S-1 was required in the GS part of treatment. Seven patients withdrew from the GS part due to progressive disease (PD), while one withdrew due to delayed dosing from BTI, and another due to a rapid clinical progression and jaundice that precluded further GS treatment.
For the total 10 patients, DLT was not observed in the CCRT part, and the MTD was not achieved. Table IV summarizes the treatment-related adverse effects (AEs) developed between the start of CCRT and before the initiation of the GS part of treatment. Hematological toxicity was not observed in any patient. The most common nonhematological toxicities were grade 1 and 2 nausea $(60 \%$, $n=6)$, vomiting $(60 \%, n=6)$, and anorexia $(30 \%, n=3)$. One short-term (within 7 days) grade 3 BTI was observed. No other grade 3 or higher toxicities were found.

During the first 3 cycles of GS, hematological toxicities were typically mild. One case of grade 4 neutropenia (11\%) requiring G-CSF and a case of grade 3 leucopenia (11\%) were observed. The most common non-hematological toxicities were nausea $(56 \%, \mathrm{n}=5)$, fatigue $(56 \%, \mathrm{n}=5)$, and anorexia $(44 \%$, $\mathrm{n}=4)$. Grade 3 or higher AEs, including abnormal liver function, were noted in 2 patients $(22 \%)$, nausea in $1(11 \%)$, vomiting in $1(11 \%)$, and intra-abdominal infection in $1(11 \%)$.

The antitumor effective of CCRT was evaluated in all 10 patients (Table III). As for control of the pancreatic tumor, 1 patient had reached local PR (dose level 4) (Figure 2), and the other 9 patients had local stable disease (SD) with an overall 


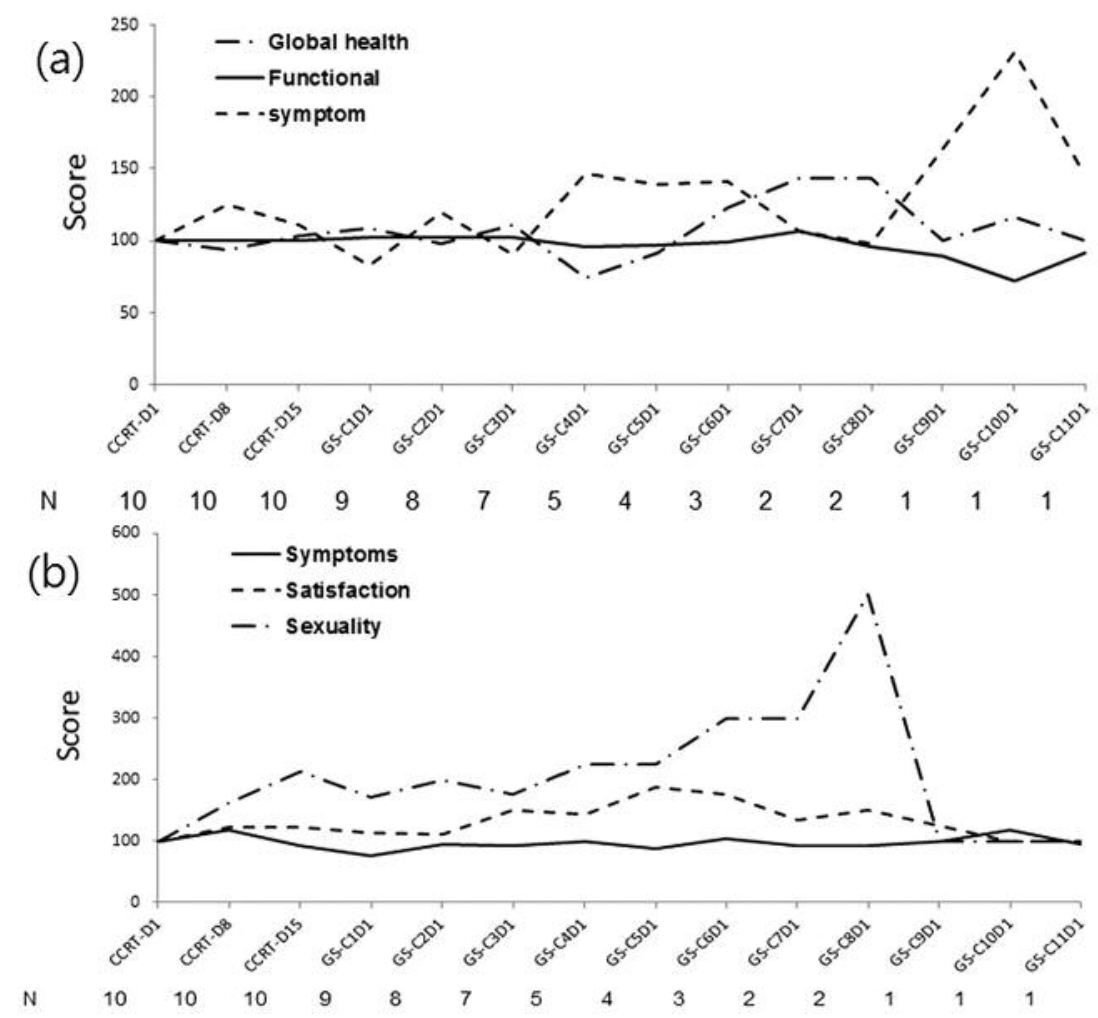

Figure 3. The dynamic change of functional status, global health, and symptoms in the QLQ-C30 questionnaire (a), and pancreatic cancer-specific symptoms, satisfaction about medical care, and sexuality in the QLQ-PAN26 questionnaire (b).

DCR of $100 \%$. Four patients $(40 \%)$ had SD at distant metastatic sites, while the other six had PD. All of these six patients with PD in distant sites had progression of liver metastases. The response of CA 19-9 after CCRT was $10 \%(n=1)$.

The antitumor response of GS was evaluated in all 9 patients receiving GS (Table III). One PR and four cases of SD were observed with a RR of $11 \%$, and a DCR of $56 \%$. None of the 10 patients had local pancreatic tumor progression before withdrawing from the study treatment. The CA 19-9 response of GS was $50 \%(n=4)$ in 8 evaluable patients.

The clinical benefit of pain control was evaluated in all 10 patients. Of the 9 patients with baseline pain score $\geq 2$, two had achieved clinical benefit in pain control and 3 had stable pain control with the overall pain control rate of $56 \%$. The other 4 patients had deteriorating pain or increasing doses of narcotics during the study. One of the 10 patients $(10 \%)$ developed bowel obstruction after the study treatment. Of the 6 patients without initial biliary obstruction requiring drainage, only one patient ( $17 \%$ ) eventually developed a new biliary obstruction before death. Three of all 10 patients (30\%) experienced a BTI during study treatment, and these 3 patients had pancreatic head tumors with biliary drainage. As shown in Figure $3 \mathrm{a}$ and $\mathrm{b}$, the global health, functional status, and pancreatic cancer-associated symptoms were maintained throughout the treatment of CCRT and GS.

The median PFS after initiation of GS was 3.0 months (95\% confidence interval [CI], 0-6.0 months). The median OS after initiation of CCRT and GS was 9.8 (95\% CI=7.312.4 months) and 8.7 (95\% CI=6.3-11.1 months) months, respectively. There was a strong association between OS and PANCES $\left(\mathrm{R}^{2}=0.758\right)$. After stratification of PANCES into low-risk ( $\leq$ median) and high-risk (>median) subgroups, patients with low-risk PANCES had significantly better OS than those with high-risk PANCES [low-risk $v s$. high-risk, $15.1(95 \% \mathrm{CI}=12.1-18.2)$ months $v s .4 .1(95 \% \mathrm{CI}=0.5-7.6)$ months, respectively, $p=0.003$; Figure 4].

All the 9 patients entering the GS part received salvage chemotherapy after disease progression from GS. The most frequently used salvage regimens were oxaliplatin $(n=5)$ or nabpaclitaxel-containing $(n=4)$ regimens. As of May 2017, 9 patients died from disease progression or disease-related complications.

\section{Discussion}

In this phase I study of S-1-based CCRT followed by GS in patients with metastatic PDAC, the MTD had not been 


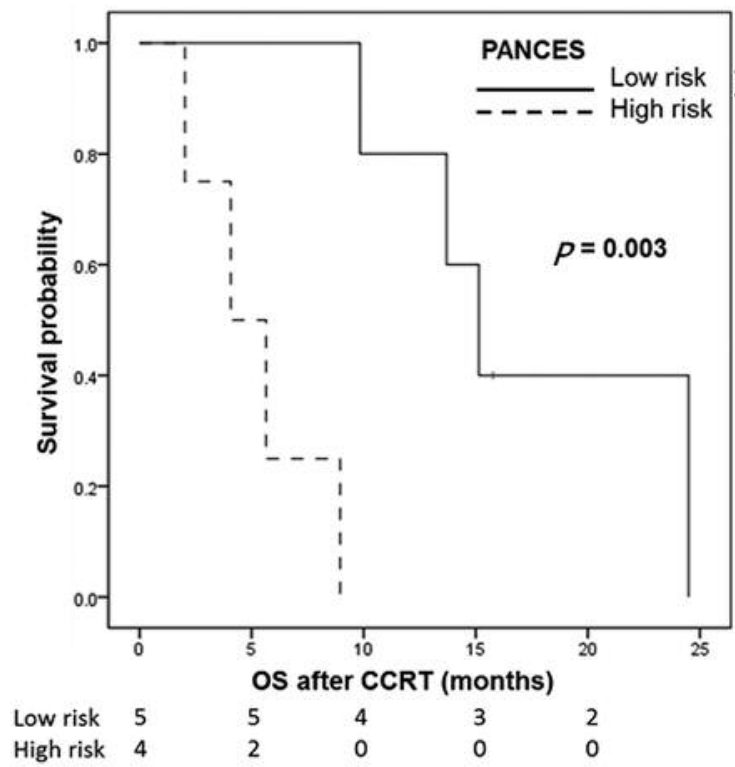

Figure 4. The overall survival stratified into low-risk PANcreatic Cancer Extent Score (PANCES) and high-risk PANCES subgroups.

identified due to early termination after enrolling the first patient at dose level $4\left(\mathrm{~S}-160 \mathrm{mg} / \mathrm{m}^{2} /\right.$ day on 16 consecutive days and RT of $36 \mathrm{~Gy}$ in 12 fractions). Similarly, a previous phase I/II study had enrolled advanced, including metastatic, PDAC to test the local tumor control and toxicity of a 5-FU and cisplatin-based hyperfractionated RT protocol (17). At a RT dose of 45 Gy in the phase II portion, significant hematological toxicities requiring G-CSF, as well as gastrointestinal toxicities were observed (17). The local DCR of all patients was high $(85 \%, 17 / 20)$. However, the median OS of the metastatic subgroup was only 5 months (17).

Even without direct comparison, S-1 probably has a higher RR than 5-FU for treatment of advanced PDAC $(1,3)$. To increase the treatment efficacy, the combined chemotherapy regimen, GS, was tested in the GEST study (3). However, the neutropenia of GS appeared more severe and prevalent when compared to gemcitabine plus 5-FU (18). Moreover, about one-fourth of patients in the GEST study had locally advanced PDAC disease (3). The nature of this disease most likely differs from metastatic PDAC (19). Furthermore, the condition of patients with metastatic disease may be more fragile than in those with locally advanced disease. Since metastatic PDAC is not curable, we lengthened the dosing intervals of gemcitabine and S-1 to reduce chemotherapyassociated toxicities. Even though the RR, DCR, and PFS of GS in our study were found to be lower than those reported in the GEST study, the median OS in our study (9.8 months) was comparable to that in the metastatic subgroup of the GEST study (9.4 months) (3). Notably, the hematological toxicities of GS were much lower in our study.
The choice of S-1 for CCRT in our study was based on the toxicity profiles and RRs in favor of $\mathrm{S}-1$ than gemcitabine in previous studies $(10,11)$. In the ECOG study examining patients with locally-advanced PDAC, $38 \%$ of patients required dose reduction of gemcitabine in combination with RT, due to grade 3 or higher hematological toxicities (10). In our study, we investigated lower doses of S-1 and shorter courses of RT with a short interval of rest before starting systemic GS to reduce toxicities. Indeed, the toxicity of CCRT in our study was mild and transient, and the local tumor growth and associated symptoms and complications were still well controlled, while preserving QOL. Interestingly, the local control in the dose level 1 was encouraging. Our results may raise the issue of further reduction of the dose and course of RT in the palliative setting of metastatic PDAC to minimize physical and psychological stress of the patients.

Conventionally, RT is rarely considered in the treatment of metastatic PDAC $(12,13)$. Rapid disease progression and deterioration of PS may be the principal concerns regarding the use of RT. In our study, while we attempted to balance treatment-related toxicities and efficacy of CCRT, we still obtained an acceptable OS in metastatic PDAC. It was noted that the patients with low-risk PANCES had longer OS than those with high-risk PANCES. In addition, the negative impact of liver metastasis on OS had been demonstrated in a phase II study of gemcitabine plus S-1 in advanced pancreatic cancer (20). These findings suggested that, for the avoidance of rapid disease progression, the utilization of our developed PANCES scoring system might be helpful to select adequate patients with metastatic PDAC for a specific treatment modality, such as our CCRT regimen followed by GS. However, further validation of the clinical use of PANCES for metastatic PDAC in prospective trials is still required.

The limitations of our study are the small sample size and the early termination of the trial. However, the toxicities, even in the dose level 4, of CCRT were still mild, with an acceptable OS for metastatic PDAC. Further exploration of this treatment regimen is warranted in a prospective trial. This includes the use of RT with $36 \mathrm{~Gy}$ in 12 daily fractions combined with S-1 followed by systemic chemotherapy with GS, in metastatic PDAC patients with a low-risk PANCES.

\section{Conflicts of Interest}

The Authors declare no conflict of interest regarding this study.

\section{Acknowledgements}

The Authors thank the TTY Biopharm and Taiho Pharmaceutical, Co., Ltd. for providing S-1, the phase I team of the National Taiwan University Hospital for execution of this trial, the Clinical Trial Center of National Taiwan University Hospital for statistical consultation, and EORTC for providing QLQ-C30 and QLQ-PAN26 questionnaires. The Authors would like to give special thanks to 
Professor Chiun Hsu of the Department of Oncology for providing us informative and intellectual opinions in the initial study design. We also thank the grant support by the Ministry of Science and Technology, Taiwan [grant number 104-2314-B-002-189-MY3 and MOST 104-2811-B-002-058]; and the grant supported by the National Taiwan University Hospital [grant number 106-S3514]. The funding sources had no involvement in the study design, collection, analysis and interpretation of data, writing of the report, and the decision to submit the article for publication.

\section{References}

1 Burris HA 3rd, Moore MJ, Andersen J, Green MR, Rothenberg ML, Modiano MR, Cripps MC, Portenoy RK, Storniolo AM, Tarassoff P, Nelson R, Dorr FA, Stephens CD and Von Hoff DD: Improvements in survival and clinical benefit with gemcitabine as first-line therapy for patients with advanced pancreas cancer: a randomized trial. J Clin Oncol 15: 2403-2413, 1997.

2 Von Hoff DD, Ervin T, Arena FP, Chiorean EG, Infante J, Moore M, Seay T, Tjulandin SA, Ma WW, Saleh MN, Harris M, Reni M, Dowden S, Laheru D, Bahary N, Ramanathan RK, Tabernero J, Hidalgo M, Goldstein D, Van Cutsem E, Wei X, Iglesias J and Renschler MF: Increased survival in pancreatic cancer with nabpaclitaxel plus gemcitabine. N Engl J Med 369: 1691-1703, 2013.

3 Ueno H, Ioka T, Ikeda M, Ohkawa S, Yanagimoto H, Boku N, Fukutomi A, Sugimori K, Baba H, Yamao K, Shimamura T, Sho M, Kitano M, Cheng AL, Mizumoto K, Chen JS, Furuse J, Funakoshi A, Hatori T, Yamaguchi T, Egawa S, Sato A, Ohashi Y, Okusaka T and Tanaka M: Randomized phase III study of gemcitabine plus S-1, S-1 alone, or gemcitabine alone in patients with locally advanced and metastatic pancreatic cancer in Japan and Taiwan: GEST Study. J Clin Oncol 31: 1640-1648, 2013.

4 Conroy T, Desseigne F, Ychou M, Bouché O, Guimbaud R, Bécouarn Y, Adenis A, Raoul JL, Gourgou-Bourgade S, de la Fouchardière C, Bennouna J, Bachet JB, Khemissa-Akouz F, PéréVergé D, Delbaldo C, Assenat E, Chauffert B, Michel P, MontotoGrillot $\mathrm{C}$ and Ducreux M; Groupe Tumeurs Digestives of Unicancer; PRODIGE Intergroup: FOLFIRINOX versus gemcitabine for metastatic pancreatic cancer. N Engl J Med 364: 1817-1825, 2011.

5 Xie DR, Yang Q, Chen DL, Jiang ZM, Bi ZF, Ma W and Zhang YD: Gemcitabine-based cytotoxic doublets chemotherapy for advanced pancreatic cancer: updated subgroup meta-analyses of overall survival. Jpn J Clin Oncol 40: 432-441, 2010.

6 Yang SH, Kuo YH, Tien YW, Hsu C, Hsu CH, Kuo SH and Cheng AL: Inferior survival of advanced pancreatic cancer patients who received gemcitabine-based chemotherapy but did not participate in clinical trials. Oncology 81: 143-150, 2011.

7 Engebretson A, Matrisian L and Thompson C: Patient and caregiver awareness of pancreatic cancer treatments and clinical trials. J Gastrointest Oncol 7: 228-233, 2016.

8 Engebretson A, Matrisian L and Thompson C: Pancreatic cancer: Patient and caregiver perceptions on diagnosis, psychological impact, and importance of support. Pancreatology 15: 701-707, 2015.

9 Chen Y, Sun XJ, Jiang TH and Mao AW: Combined radiochemotherapy in patients with locally advanced pancreatic cancer: a meta-analysis. World J Gastroenterol 19: 7461-7471, 2013.

10 Loehrer PJ Sr, Feng Y, Cardenes H, Wagner L, Brell JM, Cella D, Flynn P, Ramanathan RK, Crane CH, Alberts SR and Benson AB 3rd: Gemcitabine alone versus gemcitabine plus radiotherapy in patients with locally advanced pancreatic cancer: an Eastern Cooperative Oncology Group trial. J Clin Oncol 29: 4105-4112, 2011.

11 Sudo K, Yamaguchi T, Ishihara T, Nakamura K, Hara T, Denda T, Tawada K, Imagumbai T, Araki H, Sakai M, Hatano K, Kawakami $\mathrm{H}$, Uno T, Ito $\mathrm{H}$ and Yokosuka O: Phase II study of oral S-1 and concurrent radiotherapy in patients with unresectable locally advanced pancreatic cancer. Int J Radiat Oncol Biol Phys 80: 119125, 2011.

12 Yang SH, Guo JC, Yeh KH, Tien YW, Cheng AL and Kuo SH: Radiotherapy is associated with a favorable prognosis in daily clinical practice treating locally-advanced and metastatic pancreatic cancer. J Gastroenterol Hepatol 31: 2004-2012, 2016.

13 Worni M, Guller U, White RR, Castleberry AW, Pietrobon R, Cerny T, Gloor B and Koeberle D: Modest improvement in overall survival for patients with metastatic pancreatic cancer: a trend analysis using the surveillance, epidemiology, and end results registry from 1988 to 2008. Pancreas 42: 1157-1163, 2013.

14 Nakata E, Fukushima M, Takai Y, Nemoto K, Ogawa Y, Nomiya T, Nakamura Y, Milas L and Yamada S: S-1, an oral fluoropyrimidine, enhances radiation response of DLD-1/FU human colon cancer xenografts resistant to 5-FU. Oncol Rep 16: 465-471, 2006.

15 Aaronson NK, Ahmedzai S, Bergman B, Bullinger M, Cull A, Duez NJ, Filiberti A, Flechtner H, Fleishman SB, de Haes JC et al: The European Organisation for Research and Treatment of Cancer QLQC30: A quality-of-life instrument for use in international clinical trials in oncology. J Natl Cancer Inst 85: 365-376, 1993.

16 Fitzsimmons D, Johnson CD, George S, Payne S, Sandberg AA, Bassi C, Beger HG, Birk D, Büchler MW, Dervenis C, Fernandez Cruz L, Friess H, Grahm AL, Jeekel J, Laugier R, Meyer D, Singer MW and Tihanyi T: Development of a disease specific quality of life (QoL) questionnaire module to supplement the EORTC core cancer QoL questionnaire, the QLQ-C30 in patients with pancreatic cancer. EORTC Study Group on Quality of Life. Eur J Cancer 35: 939-941, 1999.

17 Tsujie M, Nakamori S, Tanaka E, Nagano H, Umeshita K, Dono $\mathrm{K}$, Sakon M, Inoue T, Inoue T and Monden M: Phase I/II trial of hyperfractionated accelerated chemoradiotherapy for unresectable advanced pancreatic cancer. Jpn J Clin Oncol 36: 504-510, 2006.

18 Berlin JD, Catalano P, Thomas JP, Kugler JW, Haller DG and Benson AB 3rd: Phase III study of gemcitabine in combination with fluorouracil versus gemcitabine alone in patients with advanced pancreatic carcinoma: Eastern Cooperative Oncology Group Trial E2297. J Clin Oncol 20: 3270-3275, 2002.

19 Crane CH, Varadhachary GR, Yordy JS, Staerkel GA, Javle MM, Safran H, Haque W, Hobbs BD, Krishnan S, Fleming JB, Das P, Lee JE, Abbruzzese JL and Wolff RA: Phase II trial of cetuximab, gemcitabine, and oxaliplatin followed by chemoradiation with cetuximab for locally advanced (T4) pancreatic adenocarcinoma: correlation of Smad4(Dpc4) immunostaining with pattern of disease progression. J Clin Oncol 29: 3037-3043, 2011.

20 Song H, Han B, Park CK, Kim JH, Jeon JY, Kim IG, Kim HJ, Jung JY, Kim JH, Kwon JH, Jang G, Kim HY, Kim HS, Choi DR and Zang DY: Phase II trial of gemcitabine and S-1 for patients with advanced pancreatic cancer. Cancer Chemother Pharmacol 72: 845-852, 2013.

Received June 11, 2018 Revised July 3, 2018 Accepted July 9, 2018 